ment of neurological complications over' a long period of time is also undetermined.

In conclusion it may be said that modern therapy with potent liver extract relieves the patient of his symptoms, restores a normal blood level and prevents neurological disease. The treatment is not complete without periodical radiological examination of the stomach for neoplasia. Kaplan and Rigler in autopsy studies showed the presence of carcinoma of the stomach in 12 per cent. of their cases, an incidence three times as great as the average for the same age group.

D. G. T. Hicks, M.A., B.M., M.R.C.P.

\section{LETTER: The Nursing Situation}

Mr. Douglas Robb, in your last number, stated that the problem of the shortages of nurses in the English-speaking countries is in direct relation to the woman power. This may, to some extent, be true but surely he, like so many other people, is only looking at the problem from the number of new recruits available every year.

If every girl who trained as a nurse continued to nurse (other than those who married, and even they might be expected to nurse their own families) the shortage would be overcome.

If as a means of increasing the number of nurses the training is shortened, then more people than ever will be required to train so that even the existing standards of nursing care, carried out by student nurses, may be maintained.

It is amazing to think that medical men, who expect such a high degree of intelligence and knowledge from the people on whom they rely to help them care for their patients, should really seriously think that a nurse can be trained in less than three years. It is only towards the end of that time, by constant attendance on seriously sick people, that the nurse really begins to understand what she is doing, how to recognize the slight changes in patients which are so vitally important for their welfare and how at last to know how to make a patient comfortable and to make the doctor's treatment and orders acceptable to the patient.

The principles of nursing care have to be learned while actually doing all the day to day and hour to hour duties for the patient. They cannot be learned in the classroom, although a sound theoretical knowledge is also essential. If it were otherwise, a short correspondence course would be excellent.

Hundreds of girls are training every year. They are doing excellent work while training but the tragedy is that having qualified they infinitely prefer to be receptionists, secretaries, dental attendants or nannies, and they are frequently encouraged to take these posts by doctors from whom they receive higher salaries than they would receive as nurses.

The solution, surely lies in recognizing the position of the trained nurse, from the staff nurse up to the matron, and in giving them the responsibility and salary of the posts to which they are appointed. Then, and then only, will the right type of nurse remain in nursing.

$$
\text { Clare Alexander, }
$$
Matron, The London Hospital. 